\title{
Brachytherapy and radical prostatectomy in patients with early prostate cancer
}

\author{
Adriana Souza Sérgio Ferreira ${ }^{1 *}$, Maximiliano Ribeiro Guerra ${ }^{2}$, Humberto Elias Lopes ${ }^{3}$, U-Thant Mendonça Lima ${ }^{4}$, \\ Yara Abrão Vasconcelos ${ }^{5}$, Maria Teresa Bustamante Teixeira ${ }^{2}$ \\ Oncologist, Oncology Service, Hospital Universitário, Universidade Federal de Juiz de Fora (HU-UFJF), Juiz de Fora, MG, Brazil \\ 2Professor at the Department of Collective Health, UFJF, Juiz de Fora, MG, Brazil \\ ${ }^{3}$ Professor at the Department of Surgery, UFJF, Juiz de Fora, MG, Brazil \\ ${ }^{4}$ Oncologist, Radiotherapy Service, Hospital Ascomcer, Juiz de Fora, MG, Brazil \\ ${ }^{5}$ Medical Student, UFJF, Juiz de Fora, MG, Brazil
}

Study conducted at the Universidade Federal de Juiz de Fora (UFJF), Juiz de Fora, MG, Brazil

Article received: $7 / 16 / 2014$ Accepted for publication: $7 / 23 / 2014$

*Correspondence: Address: Rua São Sebastião, 1590 Santa Helena

Juiz de Fora, MG - Brazil Postal code: $36015-410$ Phone: +55 $323217-6729$ adssf@uol.com.br

http://dx.doi.org/10.1590/1806-9282.61.05.431

\section{SUMMARY}

Introduction: this study analyzes the survival of prostate cancer patients cared for at a hospital in Minas Gerais, Brazil according to one of the following treatments: iodine-125 seed implantation or radical prostatectomy. From January 2002 to December 2005, 129 patients underwent either brachytherapy (64 patients) or surgery (65 patients).

Methods: all had prostate-specific antigen, Gleason scores and clinical stage recorded prior to treatment. Biochemical relapse was defined as prostate-specific antigen (PSA) $>0.4 \mathrm{ng} / \mathrm{mL}$ for radical prostatectomy, and any elevation equal or higher than $2 \mathrm{ng} / \mathrm{mL}$ over the PSA nadir for implanted patients. To analyze the effect of treatment on biochemical recurrence-free survival (BRFS), Kaplan-Meier curves and Cox regression were generated. Mean follow-up time was 56.1 months for patients with the implant, and 26.6 months for those operated on. BRFS in 5 years was 69\% (95\% CI: 58.18-77.45) for the whole cohort.

Discussion: when stratified according to treatment, survival of patients who had undergone brachytherapy $(79.70 \%)$ was higher to those operated on $(44.30 \%$; pvalue $=0.0056$ ). Upon multivariate analysis, independent predictors were iPSA (HR: 2.91, 95\% CI: 1,32-6,42), Gleason score (HR: 2.18, 95\% CI: 1,00-4,81) and treatment modality (HR: 2.61, 95\% CI: 1.18-5,75). Risk of biochemical failure was higher with surgery than brachytherapy, which may be related to the failure criteria adopted, which is different for each therapy, as well as the high rate of histological progression between preoperative prostate biopsy and surgical specimen.

Conclusion: it was found that brachytherapy is a good therapeutic option for low risk prostate cancer.

Keywords: brachytherapy, prostatectomy, prostatic neoplasms.

\section{INTRODUCTION}

Prostate cancer is the most frequent cancer in men. The increase in the incidence rates of this cancer in Brazil have been related to the increase in population life expectancy, the development of diagnostic methods and improved quality of the country's information systems. ${ }^{1}$ Due to screening with prostate-specific antigen (PSA), this cancer has been diagnosed at increasingly early stages, when the tumor is still confined to the prostate gland, and thus potentially treatable. ${ }^{2}$

The ideal treatment for localized prostate cancer is still the subject of controversy. The long natural history of early and low risk tumors means that not all patients require treatment, with active surveillance being recommended when life expectancy is less than 10 years. ${ }^{3}$ Many treatment alternatives can be employed for localized disease, such as radical prostatectomy, external radiation therapy and brachytherapy, all being effective in the control of the locoregional disease.

Despite the debate about the best treatment modality in patients at low to intermediate risk, and the absence of phase III quality studies about this topic, most publications strongly suggests that radical prostatectomy, external radiotherapy and brachytherapy treatments are 
equivalent in terms of biochemical control. However, exceptions should be made for the dose of external radiotherapy employed (less than $72 \mathrm{~Gy})^{4}$ and the role of brachytherapy in intermediate risk, with current guidelines that guide the indication of these treatment modalities. ${ }^{5,6}$

Brachytherapy is performed using the transperineal route, with general or epidural anesthesia. The most popularized technique is permanent seed implantation, known as low-dose brachytherapy. The two most commonly used radioisotopes are: iodine- 125 and palladium-103. It is generally used as a single treatment, with good results in cases of low or intermediate risk. ${ }^{7}$ The low energy of these isotopes guarantees social and family life of patients after implantation, almost without restrictions. The great advantage of brachytherapy is the convenience of a oneday treatment that can be performed without the need for hospitalization.

In Brazil, prostate brachytherapy is a totally underutilized treatment, and has not been included in the procedures authorized by the Brazilian public healthcare system (SUS, Unified Health System). This is mainly due to the infamous structural and personnel availability, that is to say, there are few services that have the minimum structure and professionals with technical and scientific training to perform this procedure. Moreover, despite recent adjustments, the table of SUS reimbursement values is still far short of the expectations and costs required to implement a qualified service for this purpose. ${ }^{8}$

This series represents the experience of a hospital in the southeast region of Brazil with the implantation of iodine- 125 seeds via transperineal route, guided by transrectal ultrasound treatment of patients with prostate cancer. The results obtained were compared with those of patients treated with radical prostatectomy in the same hospital and study period.

\section{Methods}

\section{Patient selection}

This is a hospital-based non-concurrent cohort study. We evaluated 129 patients with prostate cancer who underwent brachytherapy $(n=64)$ or radical prostatectomy $(n=65)$ at a reference service on the private network in Juiz de Fora (Minas Gerais) from January 2002 to December 2005.

The choice of a treatment type (brachytherapy versus surgery) was a decision taken by the patient and the doctor, after informing the patient about both therapeutic procedures.

For brachytherapy, the exclusion criteria were considered as the recommendations issued by the American College of Radiology (ACR, 2011) and the American So- ciety for Radiology Oncology (ASTRO, 2011), such as difficulty in implanting the seeds due to pubic arch interference; prior or recent transurethral resection (TUR) due to increased risk of urinary incontinence; large median lobe; bulky prostate, etc. ${ }^{5}$

Patients with prostates over 50 grams initially received three months of luteinizing hormone-releasing hormone (LHRH) blockers, in order to reduce prostate volume, and subsequently underwent implantation. ${ }^{9}$ Patients with prior transurethral resection (TUR) considered old (over one year) and/or small (at least $1 \mathrm{~cm}$ of periurethral prostate) were also subjected to implantation and included in the analysis. $^{5}$

All patients were evaluated through medical history, physical examination, digital rectal examination and serum PSA prior to treatment (iPSA). Clinical staging was based on digital rectal examination and, when clinically indicated, chest radiography, bone scintigraphy, CT-scan and/or magnetic resonance imaging (MRI) of the pelvis. The $6^{\text {th }}$ edition of the TNM 2002 was used for staging patients. ${ }^{10}$

Considerations about the procedures adopted according to treatment modality

Brachytherapy

Pre-planning for brachytherapy was conducted using the prostate dimensions obtained by transrectal ultrasonography (TRUS) to determine the overall activity of the isotope required for each patient. Implantation was performed in the operating room of the hospital, using spinal anesthesia after bowel preparation and with the patient in dorsal lithotomy position. Before implantation, patients were submitted to fixation of the scrotum and bladder catheterization.

The intra-operative planning was done after obtaining the prostate volume at the time of implantation, obtained by sequential prostate images, from base to apex, with $5 \mathrm{~mm}$ intervals acquired using TRUS with a biplane probe (B\&K, Naerum, Denmark). The total activity to be implanted was determined by a nomogram depending on the prostate volume. The number of seeds to be implanted was calculated by dividing the total activity required by the activity of each seed at the time of implant. ${ }^{11}$

The needles were positioned so as to deposit $75 \%$ of the activity in the gland periphery and $25 \%$ inside in order to obtain the modified standard peripheral load, thereby saving the urethra. The placement of the needles, with around $1 \mathrm{~cm}$ intervals, was guided via TRUS, which allows visualization of the prostate in transverse, longitudinal and oblique planes. Furthermore, these needles could be moved along the prostate under constant visualization, 
allowing precise placement of seeds. The loose seeds were implanted into the prostate with a Mick Applicator (Mick Nuclear, Bronx, New York) under TRUS visualization and, in some cases, with the aid of fluoroscopy. The prescribed dose was 144 Gy (task group [TG] 43). ${ }^{12,13}$ The radioisotope used in all patients was iodine-125, OncoSeed Model 6711 from Oncura. The activity of the seeds of iodine- 125 ranged from $0.29 \mathrm{mCi}$ to $0.465 \mathrm{mCi}$, with an average of $0.392 \mathrm{mCi}$. No patient in this series of cases received external radiation therapy before or after brachytherapy.

\section{Surgery}

Patients undergoing radical prostatectomy underwent surgery in the same hospital as per the technique described by Walsh. ${ }^{14}$ After infraumbilical incision and access to the retropubic space, the dissection of the pelvic lymph nodes was carried out. Then, after prostate exposure, the endopelvic fascia was opened, with ligation and sectioning of the dorsal venous complex. The next step was dissection and section of the urethra. The prostate was then dissected retrogradely, preserving the neurovascular bundle or not according to the clinical and surgical staging. Finally, colovesical section was performed with prostate removal and hemostasis. Vesicourethral anastomosis was performed under a urethral catheter which remained for 10 to 12 days. The average duration of hospitalization was three days.

\section{Follow-up}

The data relating to follow-up were obtained from medical records and supplemented through contact with the patient or referring physician, if necessary.

Patients undergoing brachytherapy were monitored with physical examination and serum PSA doses with an interval of 3 to 6 months in the first three years of follow-up and every 6 to 12 months, from the fourth year of follow-up. ${ }^{15}$ In relation to operated patients, who had a less frequent follow-up, those with at least one annual dose of PSA in the follow-up period were assessed.

\section{Treatment and analysis of data}

The outcome studied was biochemical recurrence-free survival. For patients undergoing brachytherapy, failure or biochemical recurrence was defined as any increase of $2 \mathrm{ng} / \mathrm{mL}$ or more in the PSA nadir, as per the Phoenix criteria. ${ }^{16,17}$ For those undergoing radical prostatectomy, biochemical recurrence was considered as obtaining any PSA greater than or equal to $0.4 \mathrm{ng} / \mathrm{mL}$. ${ }^{18-}$ ${ }^{20}$ The cases of surgical patients who needed to receive any salvage therapy during clinical follow-up, such as radiotherapy on the surgical bed or hormone therapy were also considered a failure. In these cases, the failure data was the start of salvage therapy.

The value of the PSA at the time of failure was kept as the last PSA record for that patient, discarding subsequent PSA values, because they would be influenced by androgen deprivation.

The cases confirmed as loss in the follow-up were censored on the date referring to the last follow-up recorded in the medical record. Patients who died due to causes unrelated to prostate cancer or its treatment were censored at the date of death.

The cases were stratified according to risk classification proposed by D'Amico, ${ }^{21}$ considering: low risk as patients with PSA $\leq 10 \mathrm{ng} / \mathrm{mL}$, a Gleason score $\leq 6$ and staging $\leq \mathrm{T} 2 \mathrm{a}$; intermediate risk as patients with staging of $\mathrm{T} 2 \mathrm{~b}$ or PSA between 10 and $20 \mathrm{ng} / \mathrm{mL}$, or Gleason score of 7 ; and high risk as patients with PSA $>20 \mathrm{ng} / \mathrm{mL}$ or Gleason score $\geq 8$ or staging $\geq \mathrm{T} 2 \mathrm{c} .{ }^{14,21}$

The differences in the distribution of study variables, according to the mode of treatment were evaluated by Chisquared test and, if necessary, by Fisher's exact test, considering statistical significance for those with a value of $\mathrm{p} \leq$ 0.05 . Survival probabilities were calculated according to the Kaplan-Meier method, ${ }^{22}$ with survival curve estimated for patients according to the type of therapy (brachytherapy versus surgery) and considering the variables selected for the study: age at diagnosis ( $<65, \geq 65$ years), iPSA ( $\leq 10$ and $>10 \mathrm{ng} / \mathrm{mL}$ ), Gleason score ( $\leq 6$ and $>6$ ), clinical stage (T1-T2a and $\geq \mathrm{T} 2 \mathrm{~b}$ ), risk stratification (low and intermediate/high) and neoadjuvant LHRH blocking (yes or no). ${ }^{19,23-}$ ${ }^{25}$ Log-rank test was used to determine differences between the curves for each variable.

For the evaluation of prognostic factors, we used the Cox regression model for proportional hazards, by computing hazard ratios (HR) and corresponding 95\% confidence intervals $(95 \% \mathrm{CI}){ }^{26}$ For the multivariate model, were selected the variables that presented HR with a significance level $\leq 0,05$ and those which, while not reaching the previous criteria, were considered relevant in the literature. The significance of the parameters of the reduced model was verified by the likelihood ratio test, and the proportionality of the Cox model was verified using Schoenfeld residuals test. ${ }^{27}$

We used the Epi Info 2000 program (Centers for Disease Control and Prevention, Atlanta, USA) for input and descriptive analysis of the data and Stata version 9.0, for survival analysis and prognostic factors.

The study was authorized by the ethics committee of the Federal University of Juiz de Fora (opinion report $\left.n^{\circ} 049 / 2009\right)$. 


\section{RESULTS}

We initially identified 139 patients who met the inclusion criteria for the study, and 10 of these were subsequently excluded due to lack of follow-up.

The main characteristics of the study population are shown in Table 1. Patients undergoing radical prostatectomy were aged between 48 and 74 years, with a median age of 62.5 years (standard deviation: 6.5). Patients treated with brachytherapy were aged between 54 and 85 years, with a median age of 73 years (standard deviation: 6.2) $(\mathrm{p}=0.0001)$. The distribution of patients according to $s e$ rum levels of iPSA, Gleason score and stage was similar in both divisions of the study: surgery and brachytherapy.

\begin{tabular}{|c|c|c|c|c|}
\hline Variables & $\begin{array}{l}\text { Brachytherapy } \\
\text { n (\%) }\end{array}$ & $\begin{array}{l}\text { Surgery } \\
\text { n (\%) }\end{array}$ & $\begin{array}{l}\text { Total } \\
\text { n (\%) }\end{array}$ & P-value \\
\hline \multicolumn{5}{|l|}{ Age range } \\
\hline$<65$ years & $11(17.2)$ & $37(56.9)$ & $49(37.2)$ & 0.000 \\
\hline$=65$ years & $53(82.8)$ & $28(43.1)$ & $81(62.8)$ & \\
\hline \multicolumn{5}{|l|}{ Gleason" } \\
\hline 2 a 6 & $48(75)$ & $48(73.8)$ & $96(74.5)$ & $0.798^{*}$ \\
\hline 7 & $13(20.4)$ & $14(21.6)$ & $27(20.9)$ & \\
\hline 8 a 9 & $1(1.5)$ & $3(4.6)$ & $4(3.1)$ & \\
\hline \multicolumn{5}{|l|}{ Stage $^{\#}$} \\
\hline T1c & $26(40.6)$ & $21(32.4)$ & $47(36.4)$ & $0.813^{*}$ \\
\hline T2a & $32(50)$ & $36(55.3)$ & $68(52.8)$ & \\
\hline $\mathrm{T} 2 \mathrm{~b}$ & $2(3.2)$ & $1(1.5)$ & $3(2.3)$ & \\
\hline $\mathrm{T} 2 \mathrm{c}$ & $1(1.6)$ & $2(3.1)$ & $3(2.3)$ & \\
\hline T3 & $3(4.6)$ & $4(6.1)$ & $7(5.4)$ & \\
\hline
\end{tabular}

\section{iPSA ng/mL ${ }^{\#}$}

\begin{tabular}{lllll}
\hline 0 a 4.0 & $14(21.9)$ & $12(18.5)$ & $26(20.2)$ & 0.914 \\
\hline 4.1 a 10 & $33(51.6)$ & $34(52.3)$ & $67(51.9)$ & \\
\hline$>10$ & $17(26.5)$ & $15(23.1)$ & $32(24.8)$ & \\
\hline Risk & & & & \\
\hline Low & $41(64.1)$ & $41(63.1)$ & $82(63.6)$ & $0.679^{*}$ \\
\hline Intermediate & $19(29.6)$ & $17(26.2)$ & $36(27.9)$ & \\
\hline High & $4(6.3)$ & $7(10.7)$ & $11(8.5)$ & \\
\hline
\end{tabular}

Source: research data (Ferreira et al)

Key to table: total \# ( $n$ ) of each variable differs due to the occurrence of missing data; *Fisher's exact test; $\mathrm{n}=$ number; iPSA: PSA prior to treatment.

The average PSA dosages for the group that underwent brachytherapy was 8.5 per patient and, for surgery, it was 2.8 per patient. The total number of PSA assessed was 735 . The median follow-up for patients undergoing brachytherapy was 56.1 months and 26.6 months for those undergoing surgery.
Approximately $90 \%$ of the study population had clinical stage $\leq \mathrm{T} 2 \mathrm{a}$ in the digital rectal examination and $75 \%$ of this population had Gleason score in the prostatic biopsy of $\leq 6$. Seventy four percent $(74 \%)$ of patients undergoing brachytherapy and $71 \%$ of patients who underwent surgery had PSA $\leq 10 \mathrm{ng} / \mathrm{mL}$, whose value ranged from 1.0 to $16 \mathrm{ng} / \mathrm{mL}$ and 2.8 to $37 \mathrm{ng} / \mathrm{mL}$ for patients implanted and operated, respectively. Only four patients operated on had PSA values over $20 \mathrm{ng} / \mathrm{mL}$. The median PSA was $5.6 \mathrm{ng} / \mathrm{mL}$ between the implanted patients, and 6.4 $\mathrm{ng} / \mathrm{mL}$ among patients operated on. Three patients with clinical stage T3, aged over 75 years and at high surgical risk, refused to undergo external radiotherapy and were implanted after conducting endorectal MRI, which showed no extracapsular invasion by cancer. Around $20 \%$ of patients undergoing brachytherapy displayed a previous history of prostatic surgery, transurethral resection of the prostate (TURP) or open surgery surgical interventions. These were considered old and small in all cases, ${ }^{5}$ which did not harm the quality of implantation. ${ }^{14}$

LHRH blocking was conducted in $17 \%$ of patients submitted to brachytherapy. Among patients undergoing radical prostatectomy, only one patient $(1.5 \%)$ received LHRH blocking and seven patients (10.8\%) had a history of TURP.

Among patients excluded for lack of follow-up, one belonged to the brachytherapy group and was at low risk, while nine patients belonged to the surgery group, these included seven at low risk and two at intermediate risk as per the D'Amico risk classification criteria. ${ }^{28}$

In relation to the anatomical-pathological characteristics of surgical specimens it was observed that while clinical staging indicated a percentage of $94 \%$ of disease in stages T1 and T2 in the surgery group only 77\% (50/64) of the patients had disease confined to the prostate gland in the evaluation of surgical specimen. In addition, $97 \%$ of these (63/64) had negative lymph nodes and surgical margins were positive in $29 \%(19 / 65)$ of the surgical specimens. In relation to the Gleason score, the results were underestimated in the biopsy compared to the surgical specimen, as only $17(26.2 \%)$ patients had a Gleason score $\geq 7$ in the biopsy, while $29(44.7 \%)$ had the same score as the surgical specimen.

Seventeen patients $(26.6 \%)$ who underwent prostatectomy needed to receive some salvage therapy after surgery. The time interval between surgery and commencement of salvage therapy ranged from 3 to 47 months, with a median time of 30 months (25\% percentile: 6 months and $75 \%$ : 38 months).

Among the implanted patients, the use of hormone therapy as a salvage treatment occurred in 11 patients (17.2\%), always at the time of biochemical failure. It was 
found at the last follow-up that $65.6 \%(42 / 64)$ of patients who underwent brachytherapy and $72.3 \%$ (47/65) of those undergoing prostatectomy presented no evidence of the disease.

All patients who failed were alive and under treatment with hormone therapy at the end of follow-up, except one patient who underwent prostatovesiculectomy and the analysis of the surgical specimen showed lymph nodes and seminal vesicles free of cancer, pauci-glandular prostate, preventing differentiation of the effect of secondary radiation of the cancer and preventing the evaluation of surgical margins. Among patients using hormone therapy due to biochemical recurrence, only one developed bone metastasis, with chemotherapy being performed, and one patient in this group died for reasons not related to cancer (acute myocardial infarction).

The median PSA nadir was $0.14 \mathrm{ng} / \mathrm{mL}$ among brachytherapy patients and $0.01 \mathrm{ng} / \mathrm{mL}$ among patients operated on. The median time to achieve this was 37 and 12 months for implanted and surgical patients, respectively.

Biochemical recurrence occurred in 18 patients operated on, representing $27.7 \%$ of this group. In six of these patients, there was an increase in PSA, and in 12 patients the failure was identified through salvage therapy during the follow-up (radio and/or hormone therapy).

In the evaluation of patients operated on whose treatment failed, it was observed that $77.8 \%$ had a Gleason score $\geq 7 ; 61.1 \%$ had pathological stage $\mathrm{PT} 3$ and the median value of the iPSA was $17.6 \mathrm{ng} / \mathrm{mL}$. Among the brachytherapy failures, $54.5 \%$ had a Gleason score $\geq 7 ; 72.7 \%$ were clinical stage $\mathrm{T} 2 \mathrm{a} / \mathrm{b}$ and the median iPSA value was $9.66 \mathrm{ng} / \mathrm{mL}$.

In relation to the deaths occurring among implanted patients, most were due to cardiovascular disease (73\%), and the rest due to complications from a second primary tumor. Among the patients who died of cardiovascular disease, three used neoadjuvant LHRH blocking and one used hormone therapy after failure. No deaths were observed among patients operated on, though it should be noted in this regard that the follow-up time and the age of these patients was significantly lower $(\mathrm{p}<0.05)$ compared to implanted patients.

The appearance of a second primary cancer was only studied in patients undergoing implantation, occurring in six cases, corresponding to $9.2 \%$ of the patients undergoing brachytherapy. Three of these patients had bowel cancer, one had kidney cancer, one had penis cancer, and the other brain cancer.

Biochemical recurrence-free survival (BRFS) over five years for the entire cohort (129 patients) was 68.93\% (95\%
CI: 58.18-77.45). A higher BRFS was found in patients treated with brachytherapy $(\mathrm{p}=0.0056)$, patients with serum iPSA less than $10 \mathrm{ng} / \mathrm{mL}(\mathrm{p}=0.0032)$ and patients with a Gleason score of $\leq 6$ in the prostate biopsy $(p=0.0002)$. Survival was also significantly higher in patients classified as low risk $(\mathrm{p}=0.0000)$. Although patients under the age of 65 and at earlier stages (T1-T2a) have shown better survival rates, the differences were not statistically significant. Patients who received neoadjuvant LHRH blocking had lower survival but with no significant difference compared to patients who did not receive this treatment. The survival curves stratified for the main variables are represented in Figure 1.

In the multivariate analysis (Table 2), three Cox proportional hazard models were prepared. For the modeling process, we selected the variables considered relevant and significant $\mathrm{p}<0.05$ (treatment, iPSA, Gleason score, risk classification), the relevant variables and those with a significance between 0.05 and 0.2 (stage) and those with only clinical relevance (age). The treatment modality was an independent prognostic factor for BRFS in the three models considered, and was also independently associated with the outcome in question: the iPSA measurement in models 1 and 2, and the degree of risk in model 3.

It should be noted that all variables in the three models did not violate the principle of proportionality of risks, according to the overall result of the p-value of the Schoenfeld residuals test, and the p-value was not statistically significant for any of the variables inserted in the models considered.

\section{Discussion}

BRFS over five years for the population studied was $68.93 \%$ (95\% CI: 58.18-77.45) and it was significantly higher $(\mathrm{p}=0.0056)$ in patients treated with brachytherapy $(79.70 \%$; 95\% CI 66.87-87.99), when compared to the patients operated on (44.30\%; 95\% CI: 23.28-63.47). In the multivariate analysis, the risk of biochemical recurrence also remained higher in patients undergoing surgery compared with those who underwent brachytherapy for all models considered.

In this comparative and non-concurrent study, treatment with brachytherapy led to a better BRFS in five years, compared with radical surgery. This result differs from the latest publications in the literature which, though not supported by randomized prospective studies, indicated BRFS results in five, ten and fifteen years similar to surgery, external radiotherapy and brachytherapy in patients with low-risk prostate cancer. ${ }^{15,24}$ It should be noted, however, that studies show that for implanted patients, 
A)

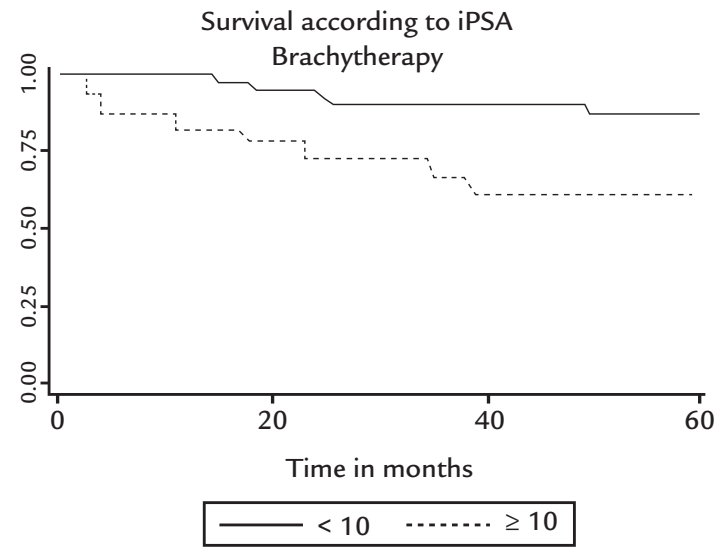

Log-rank test; $\mathrm{p}=0.0084$

C)

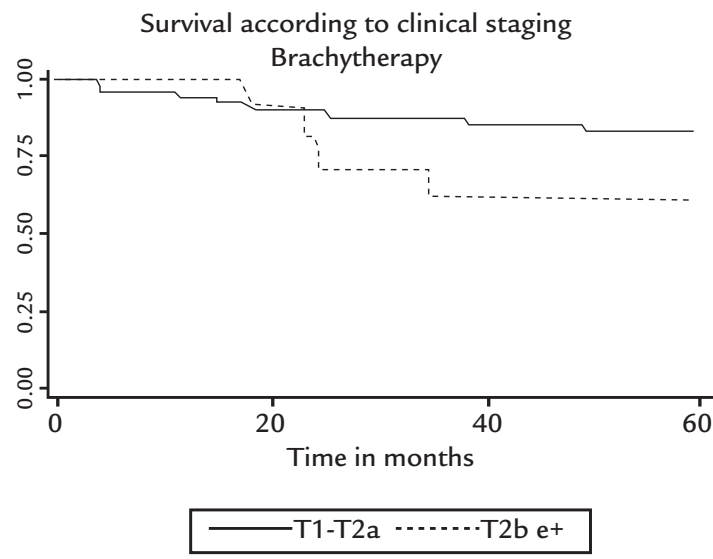

Log-rank test; $\mathrm{p}=0.1328$
B)

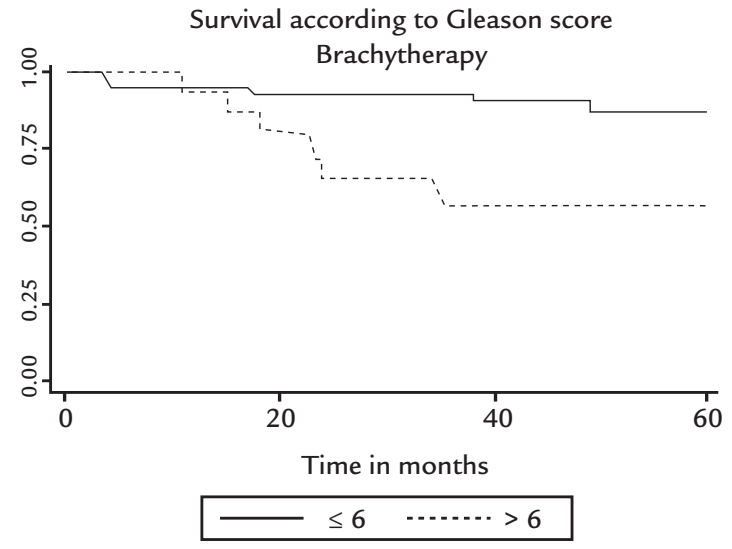

Log-rank test; $p=0.0057$

D)

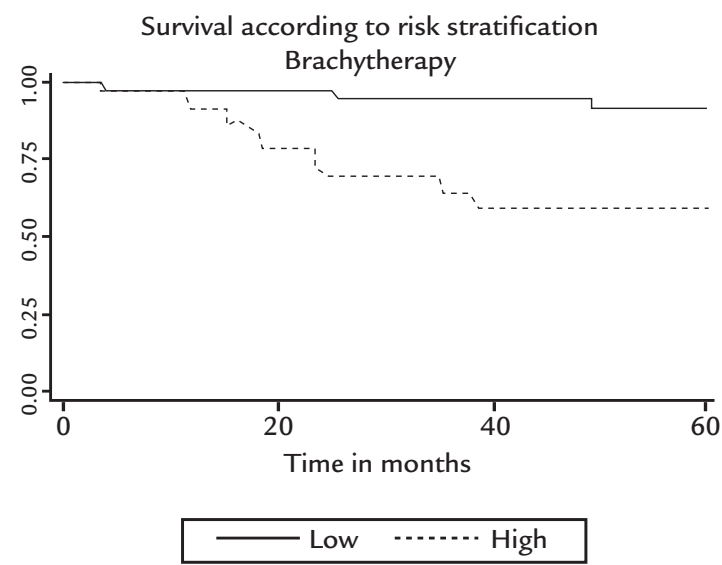

Log-rank test; $p=0.0012$

E)

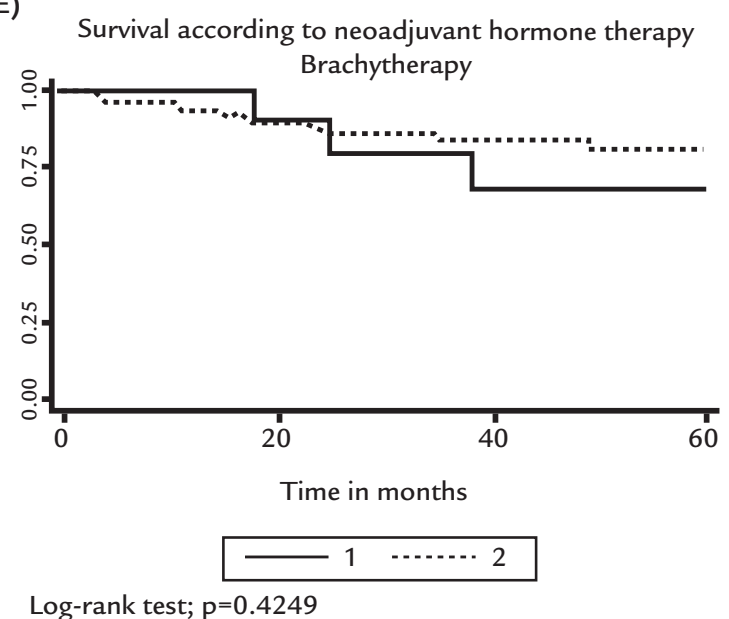

FIGURE 1 Survival curves stratified for the main variables of the study.

iPSA: PSA prior to treatment.

Source: Research data (Ferreira et al). 
TABLE 2 Unadjusted and adjusted hazard ratio (HR) of the variables that remain in the final model of Cox. Juiz de ForaMG, Brazil, 2002-2005.

\begin{tabular}{|c|c|c|c|c|}
\hline Variables & $\begin{array}{l}\text { Unadjusted } \\
\text { HR }(95 \% \mathrm{CI})\end{array}$ & $\begin{array}{l}\text { Model } 1 \text { - Adj. } \\
\text { HR (95\% CI) }\end{array}$ & $\begin{array}{l}\text { Model } 2 \text { - Adj. } \\
\text { HR (95\% CI) }\end{array}$ & $\begin{array}{l}\text { Model } 3 \text { - Adj. } \\
\text { HR }(95 \% \mathrm{CI})\end{array}$ \\
\hline \multicolumn{5}{|l|}{ Treatment } \\
\hline Brachytherapy & 1 & & & \\
\hline Surgery & $2.78(1.31-5.89)$ & $2.61(1.18-5.75)$ & $3.33(1.41-7.88)$ & $3.23(1.41-7.38)$ \\
\hline \multicolumn{5}{|l|}{ Age } \\
\hline$<65$ years & 1 & & & \\
\hline$\geq 65$ years & $1.21(0.55-2.63)$ & - & $1.91(0.74-4.97)$ & $1.80(0.76-4.24)$ \\
\hline \multicolumn{5}{|l|}{ iPSA (ng/mL) } \\
\hline$<10$ & 1 & & & \\
\hline$\geq 10$ & $3.25(1.55-6.84)$ & $2.91(1.32-6.42)$ & $2.54(1.11-5.78)$ & - \\
\hline \multicolumn{5}{|l|}{ Gleason } \\
\hline$\leq 6$ & 1 & & & \\
\hline$>6$ & $3.68(1.77-7.66)$ & $2.18(1.00-4.81)$ & $2.08(0.93-4.65)$ & - \\
\hline \multicolumn{5}{|l|}{ Risk classification } \\
\hline Low & 1 & & & \\
\hline Intermediate/high & $4.74(2.16-10.38)$ & - & - & $4.18(1.89-9.23)$ \\
\hline
\end{tabular}

iPSA: PSA prior to treatment.

Source: Research data (Ferreira et al.).

BRFS rates are widely variable according to the selection criteria adopted, ranging from $63 \%$, at 4 years, ${ }^{29}$ to $93 \%$, in five years. ${ }^{30}$ With regard to operated patients, the BRFS also varies greatly due to the pathological findings, with global BRFS rates of $81 \%$ being reported in seven years. ${ }^{31}$

Although there are many published studies that evaluate a large number of cases of low-risk prostate cancer who underwent brachytherapy, such works are very heterogeneous, since the brachytherapy technique employed in the various centers is different, and the methodology used when comparing the results from surgery and brachytherapy also differs. ${ }^{39}$ A good example of this is whether, after comparing results, operated patients receiving salvage therapy should be excluded or not, given that the inclusion of surgical patients who received radiation and/or postoperative hormone therapy can skew the results in favor of surgery.

With regard to the lower biochemical relapse rate found in patients treated with brachytherapy in this study in relation to those undergoing radical prostatectomy, this observation might be justified, at least in part, by the failure criterion used in this study, since the failure criteria were differentiated according to treatment modality. As such, it should be noted that failure included salvage therapy being instituted in patients operated on, in addition to PSA $>0.4 \mathrm{ng} / \mathrm{mL}$. It is noteworthy that the time interval between surgery and the start of this therapy had a median time of 30 months (25\% percentile: 6 months; $75 \%$ percentile: 38 months).
Furthermore, the high Gleason score found in the surgical specimens in the patients submitted to surgery, compared to the Gleason score found in the biopsy is noteworthy. Approximately $26 \%$ of the patients had a Gleason score $\geq 6$ in the prostate biopsy, while in the evaluation of the surgical specimen about $45 \%$ of patients had the same score.

It is worth remembering that the histological grade of the Gleason score of prostate adenocarcinoma is known to be one of the strongest predictors of biological aggressiveness of prostate cancer. Patients with a Gleason score of 5 to 6 but with a minority component 4 or 5 , or those with a Gleason score 7 but with a minor component 5 have higher rates of recurrence after radical prostatectomy. ${ }^{32}$ Analyzing the Gleason score in surgical specimen, we found that $46.1 \%$ had minority component 4 or 5 . Therefore, greater histological aggressiveness of tumors among patients operated on could perhaps explain part of the biochemical recurrence rates to surgical treatment observed.

In addition to the Gleason score, the prognosis after radical prostatectomy depends on the pathological findings of the tumor, such as impairment of seminal vesicles and lymph nodes by the cancer, extra-prostatic extension and surgical margins. ${ }^{31,33}$ In this study, the surgical margins were compromised in $29.2 \%$ of cases, which certainly also contributed to the higher biochemical recurrence observed. 
Therefore, this study has shown that biochemical recurrence rates were higher among operated patients and that these patients were younger, with more aggressive tumors with approximately $1 / 3$ of compromised surgical margins, and $1 / 3$ of them required salvage therapy after surgery.

There is disagreement about the importance of the age of the patient in relation to the behavior of the malignant prostate cancer. Some series show younger patients at diagnosis have more aggressive tumors. ${ }^{34,35}$ On the other hand, other studies show that survival among younger patients was equivalent or even higher than older patients. ${ }^{36,37}$ The median age of patients undergoing brachytherapy in this study was higher than that of the patients operated on $(\mathrm{p}=0.001)$, showing a current tendency of recommending this treatment only to older patients that cannot undergo surgery. In practice, the patient's age is often considered when choosing the treatment in cases of localized prostate cancer. ${ }^{38}$ Both in this study and in others, it can be seen that age has no impact on the results of brachytherapy, which proves to be a treatment with good longterm results, including patients younger than 60 years. ${ }^{19}$

In accordance with the literature, this study confirmed that the value of the initial PSA and Gleason score from the prostatic biopsy are the main independent prognostic factors for BRFS. Although the clinical stage $T$ is described as an important prognostic factor in the literature, this study failed to demonstrate the relevance of staging as an independent determinant of relapse-free survival. This fact may possibly be explained by the small sample size and/or the subjectivity of this variable, as the evaluation will vary according to the experience of the medical examiner.

All patients who failed to brachytherapy were alive and using hormone therapy (HMT) at the last follow-up, and only one, who showed a refractory disease to HMT, developed bone metastasis and began chemotherapy.

\section{Conclusion}

Supported by the results found in this study and in the literature, we can conclude that brachytherapy is as a good treatment option for patients with low-risk prostate cancer as it provides excellent biochemical control rate of the disease, while also being a less invasive method that allows the patient to return to their daily activities more quickly. Therefore, this treatment option should be encouraged and included among the treatment modalities offered by the Unified Health System, emphasizing that the inputs necessary for the incorporation of such a procedure are available in the country at low cost. ${ }^{39}$

\section{Resumo}

Braquiterapia e prostatectomia radical em portadores de câncer localizado de próstata

Introdução: este estudo avaliou a sobrevida de portadores de câncer localizado de próstata assistidos em um hospital de Minas Gerais, segundo duas modalidades terapêuticas: implante de sementes iodo-125 e prostatectomia radical. A população estudada foi de 129 pacientes tratados no período de janeiro de 2002 a dezembro de 2005 64 submetidos à braquiterapia e 65 à cirurgia.

Métodos: todos obtiveram registro do antígeno prostático específico, escores de Gleason e estadiamento clínico anterior ao tratamento. A recidiva bioquímica foi definida como PSA $>0,4 \mathrm{ng} / \mathrm{mL}$ para prostatectomia radical, e qualquer elevação de $2 \mathrm{ng} / \mathrm{mL}$ ou mais a partir do PSA nadir para os pacientes implantados. Para análise do efeito do tratamento na sobrevida livre de recidiva bioquími$\mathrm{ca}$ (SLRb), foram geradas curvas de Kaplan-Meier e foi efetuada regressão de Cox. O tempo mediano de seguimento foi de 56,1 meses para os implantados e de 26,6 meses para os operados.

Discussão: a SLRb em 5 anos para toda coorte foi de $69 \%$ (IC95\%:58,18-77,45), sendo superior para aqueles submetidos à braquiterapia $(79,70 \%)$ em relação aos operados (44,30\%; p-valor 0,0056). Na análise multivariada, os fatores preditores independentes foram iPSA (HR:2,91; IC95\%:1,32-6,42), escore de Gleason (HR:2,18; IC95\%:1,004,81 ) e modalidade de tratamento (HR:2,61; IC95\%:1,18$5,75)$. O risco de falha bioquímica foi maior com a cirurgia, comparado à braquiterapia, o que pode estar relacionado ao elevado índice de progressão histológica entre biópsia prostática pré-operatória e peça cirúrgica, e pelo critério de falha adotado, distinto para cada terapêutica.

Conclusão: foi possível constatar que a braquiterapia é uma boa opção terapêutica para o câncer de próstata de baixo risco.

Palavras-chave: braquiterapia, prostatectomia, neoplasias da próstata.

\section{References}

1. Brasil. Ministério da Saúde. Secretaria de Atenção à Saúde. Instituto Nacional de Câncer (INCA). Coordenação de Prevenção e Vigilância de Câncer. Tipo de câncer: próstata. Available at: http://www2.inca.gov.br/wps/wcm/connect/ tiposdecancer/site/home/prostata

2. Lag R, Eisner MP, Kosary CL, et al. SEER Cancer Statistics Review. National Cancer Institute. Bethesda; 2002. p.1973-999.

3. Holmberg L, Bill-Axelson A, Helgesen F, Salo JO, Folmerz P, Häggman M, et al. A randomized trial comparing radical prostatectomy with watchful waiting in early prostate cancer. N Engl J Med. 2002; 347(11):781-9. 
4. Viani GA, Stefano EJ, Afonso SL. Higher-than-conventional radiation doses in localized prostate cancer treatment: a meta-analysis of randomized, controlled trials. Int J Radiat Oncol Biol Phys. 2009; 74(5):1405-18.

5. Rosenthal SA, Bittner NH, Beyer DC, Demanes DJ, Goldsmith BJ, Horwitz EM, et al. American Society for Radiation Oncology (ASTRO) and American College of Radiology (ACR) practice guideline for the transperineal permanent brachytherapy of prostate cancer. Int J Radiat Oncol Biol Phys. 2011; 79(2):335-41.

6. American Urological Association. Prostate Cancer. Guideline for the Management of Clinically Localized Prostate Cancer: 2007 Update. Available at: http://www.auanet.org/content/guidelines-and-quality-care/clinical guidelines/main reports/proscan07/content.pdf.

7. Pereira da Ponte AL, Silva JLF, Hanna SA, Haddad CM, Nesrallah AJ, Carvalho HA. Biochemical control of prostate cancer with Iodine-125 brachytherapy alone: experience of a single institution. Clin Transl Oncol. 2012; 14(5):369-75.

8. Marta GN, Hanna SA, Silva JLF. Braquiterapia de próstata: historicamente consagrada, eficaz e subutilizada. Diagn Tratamento. 2011; 16(3):132-3.

9. Kupelian PA, Potters L, Khuntia D, Ciezki JP, Reddy CA, Reuther AM, et al. Radical prostatectomy, external beam radiotherapy $<72$ Gy, external beam radiotherapy > or $=72 \mathrm{~Gy}$, permanent seed implantation, or combined seeds/ external beam radiotherapy for stage T1-T2 prostate cancer. Int J Radiat Oncol Biol Phys. 2004; 58(1):25-33.

10. Brasil. Ministério da Saúde. Secretaria de Atenção à Saúde. Instituto Nacional de Câncer (INCA). Coordenação de Prevenção e Vigilância de Câncer. TNM: estadiamento de tumores malignos. [cited 2014 apr 23]. Available at: http:// www1.inca.gov.br/tratamento/tnm/tnm2.pdf

11. Stock RG, Stone NN, Wesson MF, DeWyngaert JK. A modified technique allowing interactive ultrasound-guieded three dimensional transperineal prostate implantation. Int J Radiat Oncol Biol Phys. 1995; 32(2):219-25.

12. Rivard MJ, Butler WM, Devlin PM, Hayes JK Jr, Hearn RA, Lief EP, et al. American Brachytherapy Society recommends no change for prostate permanent implant dose prescriptions using iodine- 125 or palladium- 103 . Brachytherapy. 2007; 6(1):34-7.

13. Nath R, Anderson LL, Luxton G, Weaver KA, Williamson JF, Meigooni AS. Dosimetry of intersticial brachytherapy sources: recommendations of the AAPM Radiation Therapy Committee Task Group no 43. American Association os Phisicists in Medicine. Med Phys. 1995; 22(2):209-34.

14. Comploj E, Pycha A. Experience with radical perineal prostatectomy in the treatment of localized prostate cancer. Ther Adv Urol. 2012; 4(3):125-31.

15. Prada PJ, González H, Fernández J, Jiménez I, Iglesias A, Romo I. Biochemical outcome after high-dose-rate intensity modulated brachytherapy with external beam radiotherapy: 12 years of experience. BJU Int. 2012; 109(12):1787-93

16. Roach M 3rd, Hanks G, Thames H Jr, Schellhammer P, Shipley WU, Sokol $\mathrm{GH}$, et al. Defining biochemical failure following radiotherapy with or without hormonal therapy in men with clinically localized prostate cancer: recommendations of the RTOG-ASTRO Phoenix Consensus Conference. Int J Radiat Oncol Biol Phys. 2006; 65(4):965-74.

17. Yoshida T, Nakayama M, Matsuzaki K, Kobayashi Y, Takeda K, Arai Y, et al. Validation of the Prostate Cancer Risk Index (PRIX): a simple scoring system to predict risk of biochemical relapse after radical prostatectomy for prostate cancer. Jpn J Clin Oncol. 2011; 41(11):1271-6.

18. Amling CL, Bergstralh EJ, Blute ML, Slezak JM, Zincke H. Defining prostate specific antigen progression after radical prostatectomy: what is the most appropriate cut point? J Urol. 2001; 165(4):1146-51.

19. Shapiro EY, Rais-Bahrami S, Morgenstern C, Napolitano B, Richstone L, Potters L. Long-term outcomes in younger men following permanent prostate brachytherapy. J Urol. 2009; 181(4):1665-71.

20. González-San S, Herranz-Amo F, Alvarez-González A, Cuesta-Álvaro P, Gómez-Espi M, Paños-Fagundo E, et al. Radical prostatectomy versus external- beam radiotherapy for localized prostate cancer: long-term effect on biochemical control-in search of the optimal treatment. Ann Surg Oncol. 2011; 18(10):2980-7.

21. D'Amico AV. Combined-modality staging for localized adenocarcinoma of the prostate. Oncology (Williston Park). 2001; 15(8):1049-59; discussion 1060-2,1064-5,1069-70,1073-5.

22. Kaplan EL, Meier P. Non-parametric estimation from incomplete observations. J Am Stat Assoc. 1958; 53(282):457-81

23. D'Amico AV, Whittington R, Malkowicz SB, Weinstein M, Tomaszewski JE, Schultz D, et al. Predicting prostate specific antigen outcome preoperatively in the prostate specific antigen era. J Urol. 2001; 166(6):21858 .

24. Kupelian PA, Potters L, Khuntia D, Ciezki JP, Reddy CA, Reuther AM, et al Radical prostatectomy, external beam radiotherapy $<72$ Gy, external beam radiotherapy > or $=72 \mathrm{~Gy}$, permanent seed implantation, or combined seeds/ external beam radiotherapy for stage T1-T2 prostate cancer. Int J Radiat Oncol Biol Phys. 2004; 58(1):25-33.

25. Ragde H, Blasko JC, Grimm PD, Kenny GM, Sylvester JE, Hoak DC, et al. Interstitial iodine- 125 radiation without adjuvant therapy for clinically localized prostate cancer. Cancer 1997; 80(3):442-53.

26. Cox DR. Regression models and life tables (life tables). J R Stat Soc. 1972; 34(1):187-9.

27. Cleves MA, Gould WW, Gutierrez RG. An introduction to survival analysis using Stata. College Sation: Stata Press Corporation, 2002.

28. Fonseca RP, Fernandes Junior AS, Lima VS, Lima SSS, Castro AF, Horta HL et al. Recidiva bioquímica em câncer de próstata: artigo de revisão. Rev Bras Cancerol. 2007; 53(2):167-72.

29. Wallner K, Roy J, Harrison L. Tumor control and morbidity following transperineal iodine-125 implantation for stage T1/T2 prostatic carcinoma. J Clin Oncol. 1996; 14(4):449-53.

30. Blasko JC, Wallner K, Grimm PD, Ragde H. Prostate specific antigen based disease control following ultrasound guided 125iodine implantation for stage T1/T2 prostatic carcinoma. J Urol. 1995; 154(3):1096-9.

31. Catalona, WJ, Smith DS. Cancer recurrence and survival rates after anatomic radical retropubic prostatectomy for prostate cancer: intermediate-term results. J Urol. 1998; 160(6 Pt 2):2428-34

32. Cheng L, Koch MO, Juliar BE, Daggy JK, Foster RS, Bihrle R, et al. The combined percentage of Gleason patterns 4 and 5 is the best predictor of cancer progression after radical prostatectomy. J Clin Oncol. 2005; 23(13):2911-7.

33. Stone NN, Stone MM, Rosenstein BS, Unger P, Stock RG. Influence of pretreatment and treatment factors on intermediate to long-term outcome after prostate brachytherapy. J Urol. 2011; 185(2):495-500.

34. Merrill RM, Bird JS. Effect of young age on prostate cancer survival: a population-based assessment (United States). Cancer Causes \& Control. 2002; 13(5):435-43.

35. Wang J, Fen WW, Hemstreet GP III. Younger age is an independent predictor for poor survival in patients with signet ring prostate carcinoma. Prostate Cancer. 2010; 2011:216169.

36. Sun L, Caire AA, Robertson CN, George DJ, Polascik TJ, Maloney KE, et al. Men older than 70 years have higher risk prostate cancer and poorer survival in the early and late prostate specific antigen eras. J Urol. 2009; 182(5):2242-9.

37. Lin DW, Porter M, Montgomery B. Treatment and survival outcomes in young men diagnosed with prostate cancer. Cancer. 2009; 115(13):2863-71.

38. Alibhai SM, Krahn MD, Cohen MM, Fleshner NE, Tomlinson GA, Naglie $\mathrm{G}$. Is there age bias in the treatment of localized prostate carcinoma? Cancer. 2004; 100(1):72-81.

39. Rostelato MECM, Rela PR, Zeituni CA, Feher A, Manzoli JE, Moura ES, et al. Development and production of radioactive sources used for cancer treatment in Brazil. Nukleonika. 2008; 53(2):S99-S103. 